\title{
Effectiveness Against White Sharks of the Rpela Personal Shark Deterrent Device Designed for Surfers
}

\author{
Craig Blount \\ Cardno (NSW/ACT) Pty Ltd, St Leonards, New South Wales, Australia, craig.blount@cardno.com.au \\ Dan Pygas \\ Cardno (NSW/ACT) Pty Ltd, St Leonards, New South Wales, Australia \\ Marcus P. Lincoln Smith \\ Cardno (NSW/ACT) Pty Ltd, St Leonards, New South Wales, Australia \\ Daryl P. McPhee \\ Faculty of Society and Design, Bond University, Gold Coast, Queensland, Australia \\ Colby Bignell \\ Oceanwise, Australia
}

See next page for additional authors

Follow this and additional works at: https://jmstt.ntou.edu.tw/journal

Part of the Fresh Water Studies Commons, Marine Biology Commons, Ocean Engineering Commons, Oceanography Commons, and the Other Oceanography and Atmospheric Sciences and Meteorology Commons

\section{Recommended Citation}

Blount, Craig; Pygas, Dan; Lincoln Smith, Marcus P.; McPhee, Daryl P.; Bignell, Colby; and Ramsey, Ocean (2021) "Effectiveness Against White Sharks of the Rpela Personal Shark Deterrent Device Designed for Surfers," Journal of Marine Science and Technology: Vol. 29: Iss. 4, Article 13.

DOI: $10.51400 / 2709-6998.1594$

Available at: https://jmstt.ntou.edu.tw/journal/vol29/iss4/13

This Research Article is brought to you for free and open access by Journal of Marine Science and Technology. It has been accepted for inclusion in Journal of Marine Science and Technology by an authorized editor of Journal of Marine Science and Technology. 
Effectiveness Against White Sharks of the Rpela Personal Shark Deterrent Device Designed for Surfers

Authors

Craig Blount, Dan Pygas, Marcus P. Lincoln Smith, Daryl P. McPhee, Colby Bignell, and Ocean Ramsey 


\title{
RESEARCH ARTICLE
}

\section{Effectiveness Against White Sharks of the Rpela Personal Shark Deterrent Device Designed for Surfers}

\author{
Craig Blount $^{a, *}$, Dan Pygas ${ }^{a}$, Marcus P. Lincoln Smith ${ }^{a, b}$, Daryl P. McPhee ${ }^{c}$, \\ Colby Bignell ${ }^{\mathrm{d}}$, Ocean Ramsey ${ }^{\mathrm{e}}$

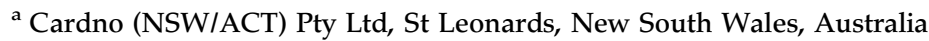 \\ ${ }^{b}$ Department of Biological Sciences, Faculty of Science and Engineering, Macquarie University, North Ryde, New South Wales, \\ Australia \\ ${ }^{c}$ Faculty of Society and Design, Bond University, Gold Coast, Queensland, Australia \\ ${ }^{\mathrm{d}}$ Oceanwise, Australia \\ e One Ocean Research and Diving, Hawaii, USA
}

\begin{abstract}
Many shark bites to humans, including fatalities, have involved surfers. Various personal shark deterrents are commercially available to surfers, including Rpela v2, which is a battery-powered device fitted to a surfboard. It produces an electric field around the surfer aimed at deterring sharks from approaching or biting by disrupting their electroreception organs. The device was tested on white sharks (Carcharodon carcharias) at Salisbury Island, Western Australia. In total, 46 trials were done with the Rpela v2 either active or not active to determine the device's effect on sharks' response to a floating board with fish bait attached (to tempt a bite). When active, Rpela v2 significantly reduced the probability of a bite ( 0.75 to 0.25 , a $66 \%$ reduction) and interaction (i.e. bite or touch) $(0.80$ to 0.50 , a $38 \%$ reduction) occurring compared with when it was inactive. The number of passes taken by a shark also reduced and the mean distance between the shark and the bait increased when Rpela v2 was active. It is noted that Rpela v2 did not completely remove the risk of shark bite, but the magnitude of the reduction in risk is of a level that surfers are likely to consider meaningful and it could be expected that Rpela v 2 would provide more time for surfers to leave the water (i.e. as inferred from the number of passes) when a potentially dangerous shark is present. Implications for the role of personal deterrents in strategic management of the risk of shark bite are also discussed.
\end{abstract}

Keywords: Unprovoked shark bite, White shark, Electric deterrent, Surfing

\section{Introduction}

$\mathrm{T}$ he occurrence of unprovoked shark bite is increasing globally due to various natural and anthropogenic factors [1-3]. Over a 30-year period unprovoked shark bite has been recorded from 56 countries and territories, with most $(84 \%)$ in the United States, South Africa, Australia, Brazil, the Bahamas and Reunion Island [3]. Many of the bites and associated fatalities have involved surfers [2,3]. White sharks (Carcharodon carcharias), tiger sharks (Galeocerdo cuvier) and bull sharks (Carcharhinus leucas) account for $55.6 \%$ of all bites (including many of the fatalities) over the 30year period [3].

There has been substantial recent investment to develop new tools to reduce the risk of shark bite to surfers. The range of products that individuals can use all claim to reduce risk by deterring sharks through disruptions to vision or smell, disrupting electro-sensitive organs by or by creating magnetic or electric fields (see [4,5]. The scientific evidence supporting the effectiveness of most devices, 
Table 1. Modifications to the Rpela.

\begin{tabular}{lll}
\hline Component & Rpela v1 & Rpela v2 \\
& Neptune Islands trials (Huveneers et al., 2018) & Salisbury Island trials (this report) \\
\hline Electrode sizes & $50 \mathrm{~cm}^{\mathrm{a}}$ & $20 \times 10 \mathrm{~cm}$ (front) and 16 $\times 16 \mathrm{~cm}$ (rear) \\
Space between electrodes & $100 \mathrm{~cm}$ & $100 \mathrm{~cm}$ \\
Voltage gradient & $200 \mathrm{~V}$ & $200 \mathrm{~V}$ \\
Magnitude of electric field @ $1.0 \mathrm{~m}$ & $0.88 \mathrm{~V}$ & $1.75 \mathrm{~V}$ \\
Frequency of discharge & $14.5 \mathrm{~Hz}$ & $9.5 \mathrm{~Hz}$ \\
Pulse duration of discharge & $0.2 \mathrm{~ms}$ & $0.2 \mathrm{~ms}$ \\
\hline
\end{tabular}

a Some changes to electrode size occurred in [7] trials, but this did not appear to affect shark responses.

however, is limited and there are few controlled studies of deterrents specifically designed for surfers apart from $[6,7]$.

It is well recognised that sharks can detect electrical fields in the water through their ampullae of Lorenzini, which are concentrated around the heads of elasmobranchs [8]. These organs are very sensitive $[8,9]$ and "overwhelming" them with an unnaturally large electrical stimulus is recognised as a potential approach to deterring sharks from biting people [10,11]. Such a stimulus does not harm a shark but may encourage a shark to rapidly move away from an area or change its behaviour. A simple human analogy is likely represented by very loud music that becomes unpleasant and encourages persons to move away from the disturbance.

The Rpela is a battery-powered device that produces an electric field around the surfer, designed specifically to deter sharks from approaching or biting the surfer. It is a water immersion-activated device fitted to the underside of a surfboard with a cable embedded in the core extending forward by one metre to a positive output electrode. Huveneers et al. (2018) tested an earlier version of the Rpela (Rpela v1) and four other shark deterrents developed for surfers by observing a number of responses including the percentage of bait taken by white sharks, time to take the bait, number of passes, distance to the bait, and whether a shark reaction (to deterrents) occurred. There was a small but non-significant, reduction in the probability of a shark reacting when Rpela was active compared with when it was not ( 0.09 vs. 0.02 of the passes).

In this paper we present the results of field testing of the efficacy of Rpela v2 and discuss the relevance of our findings to how shark bite risk could be better managed at beaches generally. Specifically, we assessed the effects of the Rpela v2 on: (1) the probability of a shark biting or interacting with the bait, (2) the number of passes a shark took prior to biting or touching (interacting) with the bait, (3) the mean distance between a shark and the bait and (4) the time sharks took to interact with the bait.
The device has been modified from that tested by [7] in terms of its electrode size, field propagation, pulse type, duration and frequency (Table 1). With an electrode size of $50 \mathrm{~cm}$ and a discharge frequency of $14.5 \mathrm{~Hz}$, this limited the electric field strength and ability of Rpela v1 to recharge between pulses. By reducing the electrode size and reducing the discharge frequency, the strength of the electric field produced by Rpela v2 has effectively doubled, as measured using the voltage at $1 \mathrm{~m}$ from the device.

\section{Methods}

All electromagnetic field testing was conducted in coastal waters of Perth, Western Australia ( $31^{\circ} 50^{\prime}$ $\left.21.59^{\prime \prime} \mathrm{S}, 115^{\circ} 46^{\prime} 44.18^{\prime \prime} \mathrm{E}\right)$. During testing the water temperature was $17.6{ }^{\circ} \mathrm{C}$ and salinity $35,000 \mathrm{ppm}$. Effectiveness trials were done on the western and eastern sides of Salisbury Island in the Recherche Archipelago off the south coast of Western Australia $\left(34^{\circ} 21^{\prime} 39^{\prime \prime} \mathrm{S}, 123^{\circ} 33^{\prime} 01^{\prime \prime} \mathrm{E}\right)$. Twenty-five trials were done on each of two trips, 29-30 March 2018 and 24-25 April 2018 (Table 2). The weather during the trials was good and the seas were calm (i.e. $<1 \mathrm{~m}$ ). Trials occurred between 0700 and 1700 each day.

The Rpela v2 was deployed using a custom-built floating test board, using dimensions made with the same material as [7] (Fig. 1). The test board was $120 \mathrm{~cm} \times 30 \mathrm{~cm}$ and made of polystyrene foam covered with layers of fibreglass cloth and epoxy resin and strengthened with wood on the sides where the bait was attached. Apart from the method

Table 2. Number of trials done on each day.

\begin{tabular}{lll}
\hline Date & No. Trials & \\
\cline { 2 - 3 } & Active & Control \\
\hline 29 March 2018 & 6 & 8 \\
30 March 2018 & 4 & 6 \\
24 April 2018 & 4 & 6 \\
25 April 2018 & 5 & 7 \\
Total & 19 & 27 \\
\hline
\end{tabular}




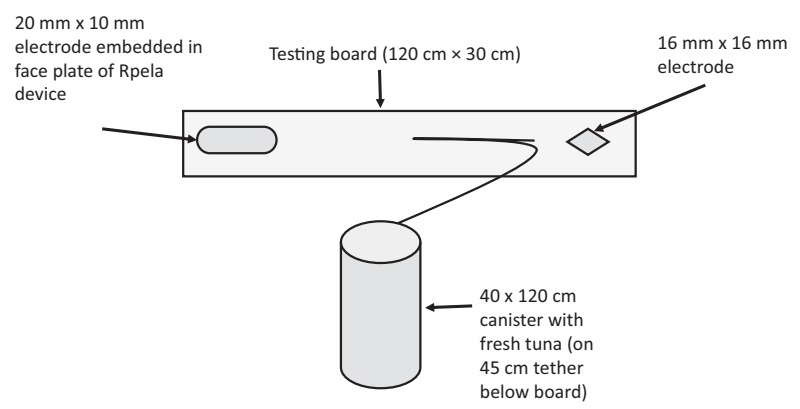

Fig. 1. Illustration of the test board set-up (not to scale).

used to attract sharks, the trial methods closely followed [7]. White sharks were first attracted to the stern of an anchored vessel with raw tuna that had been allowed to drift from the stern of the vessel and by tapping a metal pole against the hull. When a white shark was sighted near the vessel at least twice within $5 \mathrm{~min}$ or when a shark showed consistent interest in the tethered bait the bait was removed and replaced with the test board. This was only deployed when the shark had left the proximity of the vessel and was not immediately visible. In each trial, a piece of tuna $(\sim 2 \mathrm{~kg})$, referred to as the 'bait', was placed in a $40 \mathrm{~cm}$ wide $\times 120 \mathrm{~cm}$ long canister hung on a tether $\sim 45 \mathrm{~cm}$ beneath the test board (i.e. typical distance between a surfer's foot and the board). The board was attached to the stern of the anchored vessel, and left to drift with the wind and tide. The distance of the surfboard from the vessel varied between 5 and $15 \mathrm{~m}$ depending on the wind, swell and tide, and was sufficient for observers on the vessel to identify sharks and record their behaviour accurately. Trials lasted $15 \mathrm{~min}$ or until a shark touched the bait or board with an intent to consume the bait. Trials were excluded from the analysis if a shark did not approach the surfboard with an intent to take the bait. This ensured the results were not biased by trials in which sharks were not interested in the bait. During each trial, a video unit was deployed from the stern of the boat $\sim 50 \mathrm{~cm}$ below the surface and overhead to film and record each trial. The video units consisted of two GoPro Hero4 Silver edition cameras. Trials where the Rpela v2 was switched off provided the experimental control. A total of 50 trials were undertaken randomised across active and control. Equipment failure meant that video was available for 19 active and 27 control trials across the two trips (see above).

The following terminology was used to describe and code shark behaviour viewed on the video footage, following $[7,10]$ :
- Pass: a directed swim towards the experimental set-up (each time a shark veered away from the board and swam back it was classified as a new pass);

- Shark identity: Scientists identified individual white sharks based on markings on five morphological areas: caudal fin, pelvic fins, first dorsal fin (hereafter dorsal fin), gills, and pectoral fins using established white shark identification methods [12,13]; and

- Distance to bait: distance from the sharks' nose, where sensory organs susceptible to the deterrent (ampullae of Lorenzini, nostrils) are located, to the top of the bait; scientists estimated this from both visual observation and an overhead Gopro camera with reference to the size of the board. Prior to analysis, passes were removed that had low intent or that were deep and not directed at the board to avoid including behaviours where sharks were not attempting to consume the bait.

Statistical analyses were used to test differences in the probability of sharks biting the bait or interacting (i.e. biting or touching) with the bait when the Rpela v2 was active and not active (control). Also, when sharks bit or interacted with the bait, whether there was a significant difference in the number of passes prior to doing so. Further, whether there was a significant difference in the number of passes or mean distance between the shark and bait (averaged across all passes) regardless of whether a bite or interaction occurred. Differences in probabilities and numbers of passes were examined using generalised linear mixed modelling (GLMM) using the lme4 package in $\mathrm{R}$ programming environment. A binomial, Poisson, Gaussian error distribution was used for probability of bites and interactions, for numbers of passes and for mean distance, respectively. The fixed effect of primary interest was Rpela v2 status (Active or Not Active). Given that some individual sharks participated in more than one trial, trial number was also included as a fixed integer covariate to investigate the presence of potential habituation to the experimental set-up (e.g. whether particular sharks became more or less responsive to the deterrent or if there was positive reinforcement associated with the bait through time). The interaction of Rpela status and Trial No. was also included to examine whether there was an effect of Rpela status on any habituation. Individual shark was included as a random effect to account for potential lack of independence in shark behaviour among individuals. The most parsimonious model 
was selected by comparison of Akaike Information Criterion corrected for small sample sizes (AICc) values with the model with lowest value (at least by 2 AICc values) selected disregarding models with uninformative parameters. This meant that when competing models were within 2 AICc, the one with the fewest number of predictors was selected as the predictor did not explain enough variation to justify its inclusion [14]. The presence of potential habituation was also explored graphically by plotting the number of passes undertaken by each shark and the mean distance between the shark and bait for each trial where there were more than two interactions (i.e. for sharks M1, M2, M3 and M4). The significance of model parameters was corroborated using the likelihood ratio test (LRT). The LRT statistic is twice the log of the likelihoods ratio, or twice the difference in the log-likelihoods. This statistic is chisquared distributed under the null hypotheses with degrees of freedom (df) equal to df full model - $\mathrm{df}$ null model. Statistical significance was determined at $\mathrm{P} \leq 0.05$. Following model selection, parameter estimates and their statistical significance were examined to determine the influence of Treatment and Trial No. on probabilities, number of passes and distance.

\section{Results}

A total of 388 passes from a total of seven individual sharks were recorded in the 46 trials. Most passes occurred at the surface. All sharks were males and ranged in size from $2.4 \mathrm{~m}$ to $3.6 \mathrm{~m}$.

When active the Rpela v2 significantly reduced the probability of a bite occurring from approximately $0.75( \pm 0.09 \mathrm{SE})$ to $0.25( \pm 0.11 \mathrm{SE})$ (Tables 3 and 4 and Fig. 2a). The significant effect of Trial No. also indicated a reduction in the probability of a bite with time irrespective of Rpela v2 activity (Tables 4 and 5).

The probability of an interaction occurring reduced from $0.83( \pm 0.07 \mathrm{SE})$ to $0.47( \pm 0.12 \mathrm{SE})$ when Rpela v2 was active (Tables 3-5, Fig. 2b). Trial No. did not affect the probability of an interaction. For those sharks that interacted with the bait more than once, there was no obvious trend for an increase or decrease in the number of passes before an interaction that could otherwise have indicated habituation (Fig. 3). Among the sharks, the number of

Table 3. Akaike Information Criterion (AICc) values for each model. Bold text indicates most parsimonious model (see Methods).

\begin{tabular}{|c|c|}
\hline Model & $\mathrm{AICc}$ \\
\hline \multicolumn{2}{|l|}{ Probability of Bite } \\
\hline Bite $\sim$ Treatment & 63.09 \\
\hline Bite $\sim$ Trial No. & 63.42 \\
\hline Bite $\sim$ Treatment + Trial No. & 57.24 \\
\hline Bite $\sim$ Treatment $*$ Trial No. & 59.01 \\
\hline \multicolumn{2}{|l|}{ Probability of Interaction } \\
\hline Interaction $\sim$ Treatment & 58.73 \\
\hline Interaction $\sim$ Trial No. & 62.05 \\
\hline Interaction $\sim$ Treatment + Trial No. & 57.99 \\
\hline Interaction $\sim$ Treatment $*$ Trial No. & 60.46 \\
\hline \multicolumn{2}{|l|}{ No. of Passes Before Bite } \\
\hline No. of Passes Before Bite $\sim$ Treatment & 123.72 \\
\hline No. of Passes Before Bite $\sim$ Trial No. & 119.34 \\
\hline No. of Passes Before Bite $\sim$ Treatment + Trial No. & 118.40 \\
\hline No. of Passes Before Bite $\sim$ Treatment $*$ Trial No. & 119.87 \\
\hline \multicolumn{2}{|l|}{ No. of Passes Before Interaction } \\
\hline No. of Passes Before Interaction $\sim$ Treatment & 154.77 \\
\hline No. of Passes Before Interaction Trial No. & 151.78 \\
\hline No. of Passes Before Interaction $\sim$ Treatment + Trial No. & 148.21 \\
\hline No. of Passes Before Interaction $\sim$ Treatment * Trial No. & 137.84 \\
\hline \multicolumn{2}{|l|}{ No. of Passes (Total) } \\
\hline No. of Passes $\sim$ Treatment & 286.50 \\
\hline No. of Passes $\sim$ Trial No. & 281.48 \\
\hline No. of Passes $\sim$ Treatment + Trial No. & 276.77 \\
\hline No. of Passes $\sim$ Treatment * Trial No. & 273.74 \\
\hline \multicolumn{2}{|l|}{ Distance } \\
\hline Distance $\sim$ Treatment & 87.72 \\
\hline Distance $\sim$ Trial No. & 89.60 \\
\hline Distance $\sim$ Treatment + Trial No. & 83.40 \\
\hline Distance $\sim$ Treatment $*$ Trial No. & 89.57 \\
\hline
\end{tabular}


Table 4. Results of Likelihood Ratio Tests, with the log-likelihood (LogLik) of the null and full model, the chi-squared test statistic (Chisq) and associated $P$ value $(P)$. Statistical significance at $P \leq 0.05$ indicated by bold type. Degrees of freedom(df) for each test $=1$.

\begin{tabular}{|c|c|c|c|}
\hline Model & LogLik & Chisq & $\mathrm{P}$ \\
\hline \multicolumn{4}{|l|}{ Probability of Bite - Treatment } \\
\hline Bite $\sim$ Trial No. (Null Model) & -28.422 & & \\
\hline Bite $\sim$ Trial No. + Treatment & -24.130 & 8.583 & 0.003 \\
\hline \multicolumn{4}{|l|}{ Probability of Bite - Trial No. } \\
\hline Bite $\sim$ Treatment. (Null Model) & -28.257 & & \\
\hline Bite $\sim$ Trial No. + Treatment & -24.130 & 8.254 & 0.004 \\
\hline \multicolumn{4}{|l|}{ Probability of Interaction - Treatment } \\
\hline Interaction $\sim 1$. (Null Model) & -29.043 & & \\
\hline Interaction $\sim$ Trial No. + Treatment & -26.081 & 5.924 & 0.015 \\
\hline \multicolumn{4}{|l|}{ No. of Passes Before Bite } \\
\hline No. of Passes Before Bite $~ 1$ (Null Model) & -59.544 & & \\
\hline No. of Passes Before Bite $\sim$ Trial No. & -56.099 & 6.891 & 0.009 \\
\hline \multicolumn{4}{|l|}{ No. of Passes Before Interaction } \\
\hline No. of Passes Before Interaction $\sim$ Treatment + Trial No. (Null Model) & -69.291 & & \\
\hline No. of Passes Before Interaction $\sim$ Treatment $*$ Trial No. & -62.720 & 13.142 & $<0.001$ \\
\hline \multicolumn{4}{|l|}{ No. of Passes (Total) } \\
\hline No. of Passes $\sim$ Treatment + Trial No. (Null Model) & -132.63 & & \\
\hline No. of Passes $\sim$ Treatment * Trial No. & -129.79 & 5.680 & 0.017 \\
\hline \multicolumn{4}{|l|}{ Distance - Treatment } \\
\hline Distance $\sim$ Trial No. (Null Model) & -34.413 & & \\
\hline Distance $\sim$ Trial No. + Treatment & -28.867 & 11.091 & $<0.001$ \\
\hline \multicolumn{4}{|l|}{ Distance - Trial No. } \\
\hline Distance $\sim$ Treatment. (Null Model) & -36.878 & & \\
\hline Distance $\sim$ Trial No. + Treatment & -28.867 & 16.022 & $<0.001$ \\
\hline
\end{tabular}

passes before an interaction ranged from 1 to between 6 and 11. During passes, distances between shark and bait ranged up to $3.0 \mathrm{~m}$ and there were no obvious trends for an increase or decrease in distance between sharks and baits during passes that could otherwise have indicated habituation (Fig. 4).

The model containing only Trial No. was selected as the most parsimonious model of No. of passes before a bite (Table 3). There was a significant positive effect of Trial No. on number of passes before a bite irrespective of Rpela v2 status (Tables 4 and 5).

There was an increase in the number of passes before an interaction from $3.1( \pm 0.4$ SE) to $5.6( \pm 0.8$ SE) when Rpela was active (Table 3, Table 4, Fig. 2d). There was also an increase in the number of passes with Trial No. when Rpela v2 was not active, but no change when it was active.

The number of passes that a shark took irrespective of whether a bite or interaction occurred increased from $6.1( \pm 0.6 \mathrm{SE})$ to $11.0( \pm 1.0 \mathrm{SE})$ when Rpela v2 was active (Tables $3-5$, Fig. 2e). A significant interactive effect of Treatment and Trial No. was associated with an increase in the number of passes with time when Rpela v2 was not active but not when it was active (Tables 4 and 5). The distance between shark and bait increased from $0.85( \pm 0.11$ $\mathrm{SE}) \mathrm{m}$ to $1.3( \pm 0.13 \mathrm{SE}) \mathrm{m}$ when Rpela $\mathrm{v} 2$ was active (Fig. 2f). A significant effect of Trial No. was due to an increase in distance through time irrespective of Rpela v2 activity (Tables 3 and 4).

\section{Discussion}

The reduction in the probability of a bite and interaction occurring, the greater number of passes before interactions and the greater distance between the sharks and the board demonstrate the effectiveness of the Rpela v2 deterrent. Such effects would reduce the potential of bite or interaction occurring and would give a surfer more opportunity to leave the water prior to a bite or an interaction if in the presence of a dangerous shark. While the increase in distance between the shark and bait reported here (from approximately $0.8 \mathrm{~m}$ to $1.3 \mathrm{~m}$ ) was less than that reported by Huveneers et al. (2018) for the Surf + at Neptune Islands (from approximately 1.6 to $2.6 \mathrm{~m}$ ), proportionally, both devices reduced the distance by the same amount (by around 38\%).

Rpela v1 was evaluated along with a number of other personal shark deterrents by Huveneers et al. (2018). Following these trials, the Rpela v1 device was modified (Rpela v2). These modifications appear to have improved its effectiveness, however, direct testing between Rpela v1 and Rpela v2 would be required to confirm this. Nevertheless, in the current trial, the Rpela v2 significantly reduced the probability of a bite from white sharks from 0.75 
a) Probability of Bite

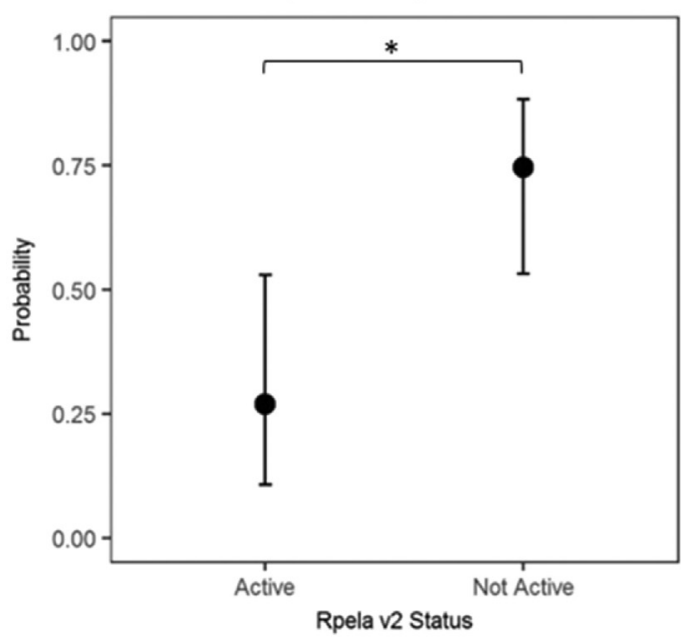

c) No. of Passes Before Bite

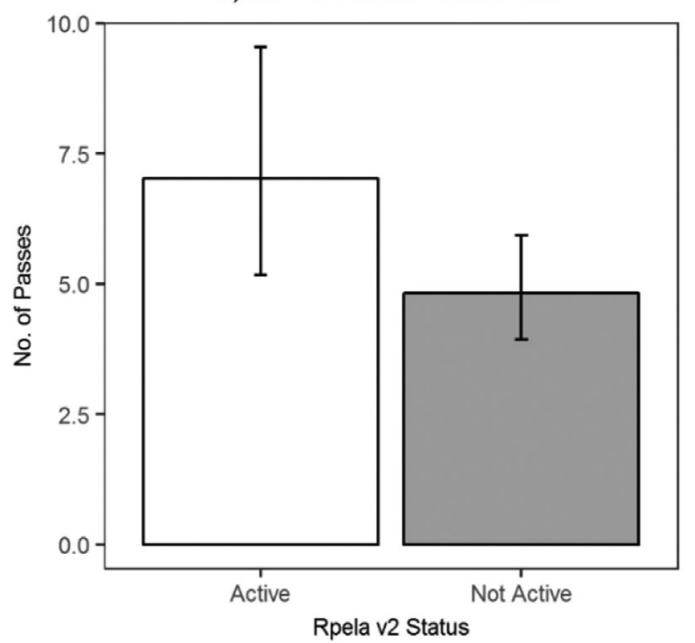

e) No. of Passes

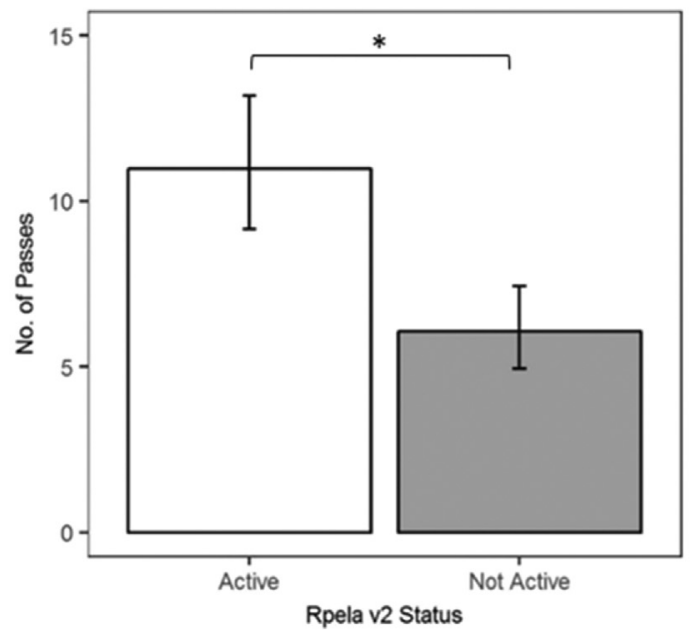

b) Probability of Interaction

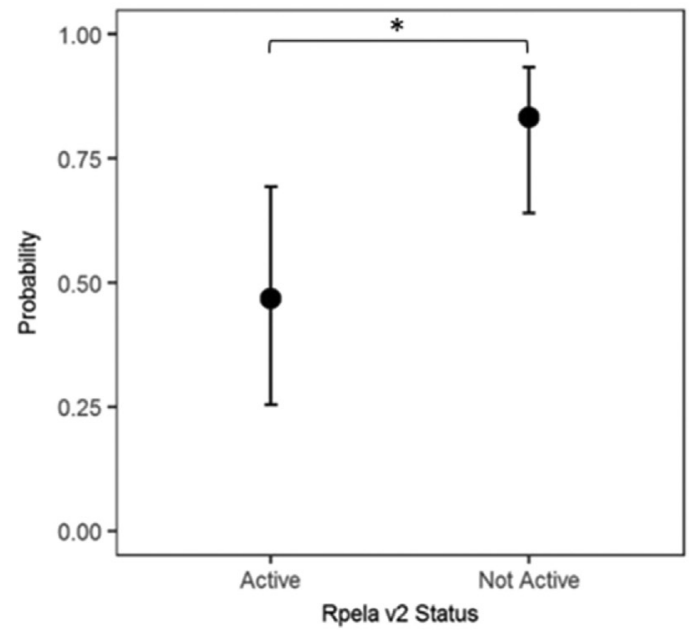

d) No. of Passes Before Interaction

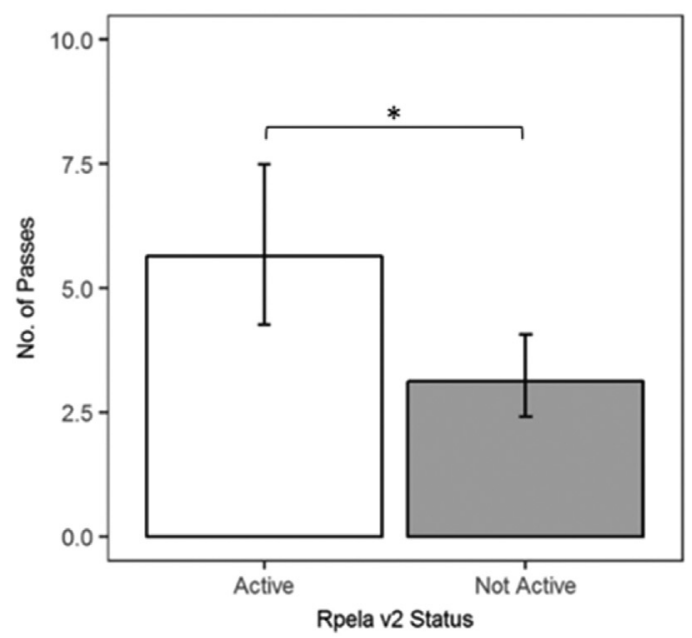

f) Distance Between Shark and Bait

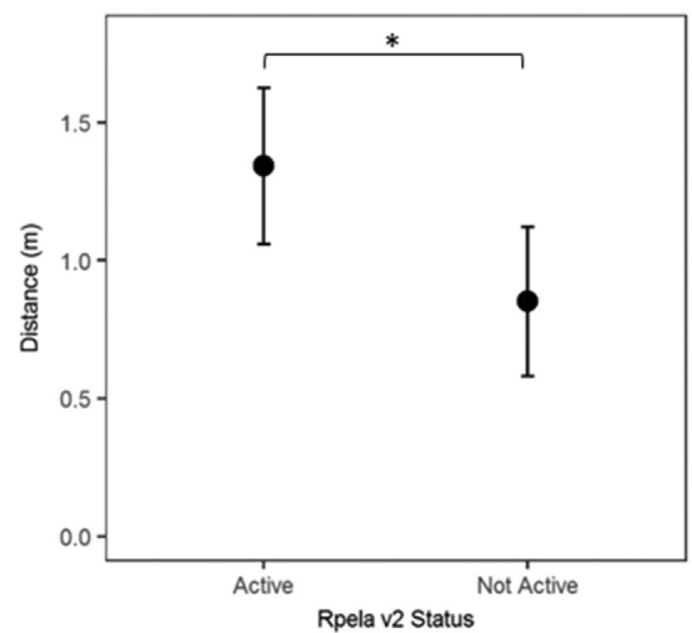

Fig. 2. a) mean probability of bite and b) interaction occurring, the number of passes c) prior a bite, d) prior to interaction e) and in total, and f) mean distance between sharks and bait when Rpela $v 2$ was active and not active. Bars indicate $95 \%$ confidence intervals and * a significant difference at $P \leq 0.05$. 
Table 5. Parameter estimates and their significance for most parsimonious models. Bold type indicates statistical significance at $\mathbf{P} \leq \mathbf{0 . 0 5}$. $Z$-Value $=$ Wald test statistic, $T$-Value $=T$ test statistic, $S E=$ standard error.

\begin{tabular}{|c|c|c|c|c|}
\hline Fixed Effect & Estimate & SE & Z-Value & $\mathrm{P}$ \\
\hline \multicolumn{5}{|l|}{ Probability of Bite } \\
\hline Treatment (Active vs. Not Active) & 2.075 & 0.779 & 2.664 & 0.008 \\
\hline \multicolumn{4}{|l|}{ Probability of Interaction } & 0.010 \\
\hline \multicolumn{4}{|l|}{ Number of Passes Before Bite } & 0.016 \\
\hline \multicolumn{4}{|l|}{ Number of Passes Before Interaction } & 0.005 \\
\hline Treatment (Active vs. Not Active) & -1.740 & 0.408 & -4.267 & $<0.001$ \\
\hline Trial No. (Active) & -0.002 & 0.014 & -0.125 & 0.901 \\
\hline Trial No. (Not Active) & 0.072 & 0.020 & 3.528 & $<0.001$ \\
\hline \multicolumn{5}{|l|}{ Number of Passes (Total) } \\
\hline Treatment (Active vs. Not Active) & -1.285 & 0.366 & -3.509 & $<0.001$ \\
\hline Trial No. (Active) & 0.009 & 0.009 & 0.949 & 0.343 \\
\hline Trial No. (Not Active) & 0.032 & 0.013 & 2.440 & $<0.015$ \\
\hline Distance & & & T-Value & \\
\hline Treatment (Active vs. Not Active) & -0.490 & 0.139 & -3.516 & $<0.001$ \\
\hline Trial No. & 0.024 & 0.005 & 4.403 & $<0.001$ \\
\hline
\end{tabular}

down to 0.25 (a reduction of $66 \%$ ) and an interaction (touch or bite) from 0.80 to 0.50 (a reduction of $38 \%$ ).

It is noted that the chance of unprovoked shark bite in areas where dangerous shark species occur cannot be reduced to zero in all circumstances by a personal shark deterrent. To be effective a personal shark deterrent will need to reduce the probability of an unprovoked shark bite by a meaningful magnitude. Reductions to risk in the current trials were much greater than the $15 \%$ minimum that [7] suggested would likely be needed to gain the confidence of the public.

A reduction in the risk of an unprovoked shark bite due to a personnel deterrent should be demonstrated through independent and ethical field trials. However, the small populations of white sharks in any area does generally limit any trial to a relatively small number of sharks. As such [7], discussed two potential analytical biases in the data collected in these types of trials associated with potential statistical non-independence from the same shark participating in more than one trial and/ or habituation. Unlike [7] we found a generally small effect due to individual sharks (as indicated by examination of the shark random effect), suggesting that non-independence was not of concern here. Nevertheless, only seven sharks were involved in the current study and although they all showed similar behavioural responses to Rpela v2, the small sample size along with the one-off nature of the trial limits inferences to other localities and populations. In [7]; variable behaviour in response to deterrents was noted among some of the 44 sharks studied, with similar findings noted previously $[10,15]$. These researchers emphasised the need to ensure that testing is done on a sufficient number of individuals to identify and account for varied responses among sharks. Although we envisage that the findings of this study would be applicable to circumstances involving other sharks, locations and seasons, the role of such factors should be examined in future studies to provide further confidence around the effectiveness of Rpela v2 over the range of scenarios it could be used in. Although such additional studies would ideally be done in coastal areas where surfers are active and in a less extreme situation (i.e. without fish bait), there are practical and ethical limitations to this. Given the need for sufficient replicates to allow robust statistical analyses, trialling requires the use of berley to attract sufficient numbers of sharks. Ethically, shark attraction trials that use fish baits should not be undertaken in coastal areas where there are other water users nor with real surfboards given there would be a risk of not only attracting potentially dangerous sharks to popular areas but also that sharks may associate a food reward with surfboards.

A significant effect of trial number was often detected in the current trials, indicating that habituation to the experimental set up may occur. Importantly, given this was not specific to when the device was active it was not considered due to the device. The evidence of a reduction in the probability of a bite, increase in the number of passes before a bite and increase in distance between shark and the bait through time, regardless of the Rpela v2 status, could suggest sharks became more wary of the experimental set up over the course of the experiment. This could possibly be due an effect of the Rpela v2 device to discourage sharks when the 
a) M1

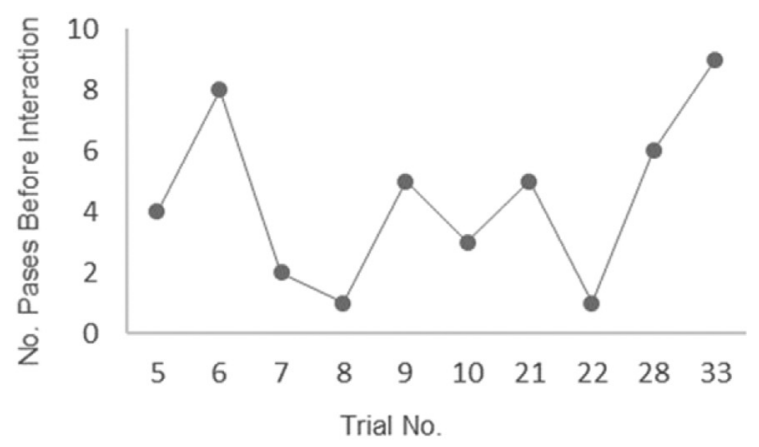

b) $\mathrm{M} 2$

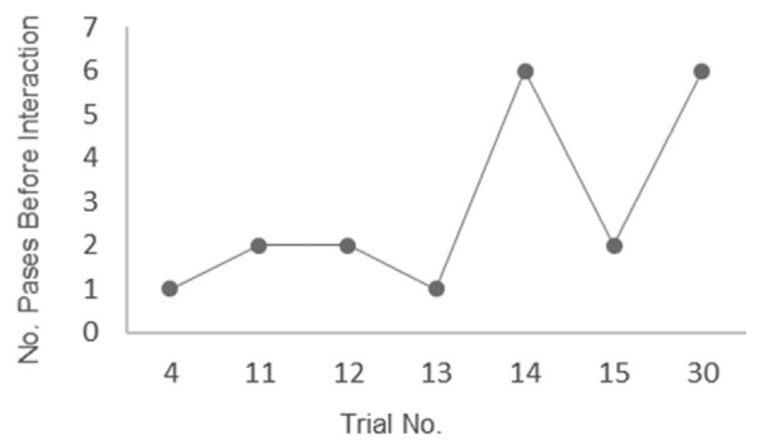

c) $\mathrm{M3}$

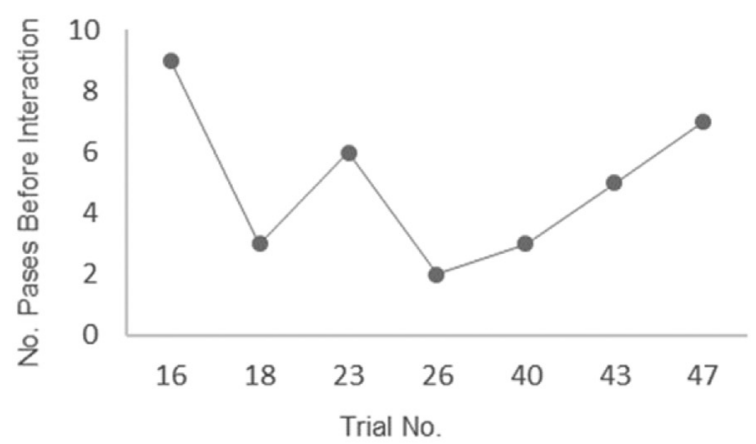

d) M4

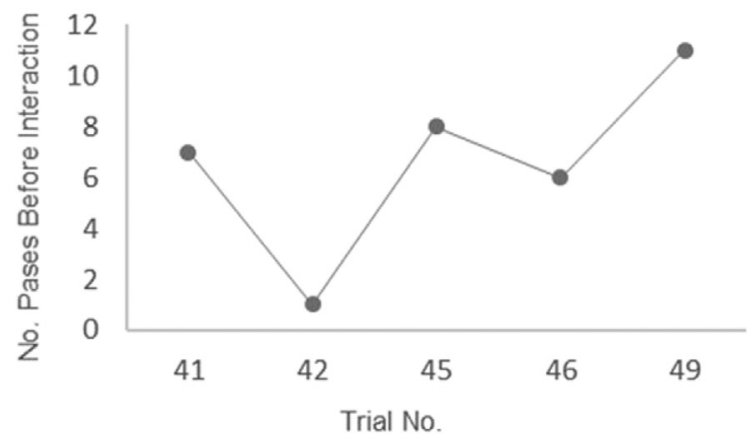

Fig. 3. Number of passes before interaction for trials where sharks M1 to M4 (those with more than 1 interaction) interacted with the bait. Includes data from trials where Rpela $v 2$ was active and not active. a) $\mathrm{M1}$

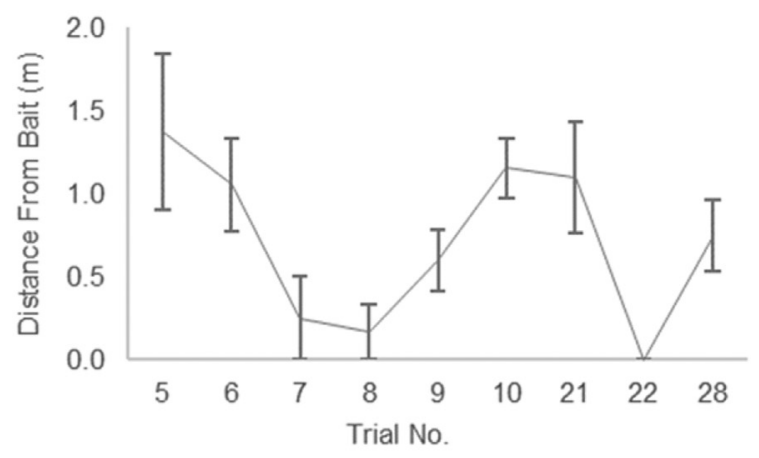

b) $\mathrm{M} 2$

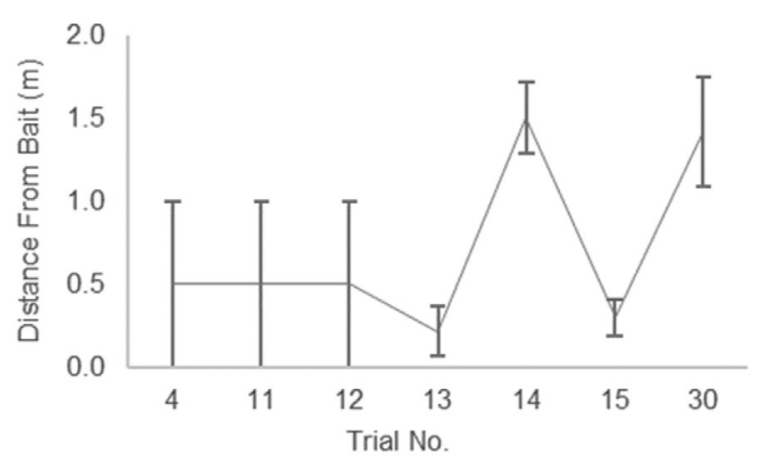

c) M3

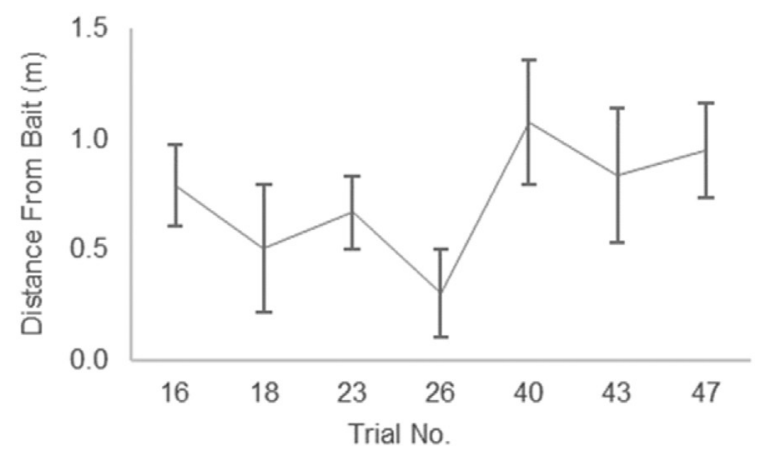

d) M4

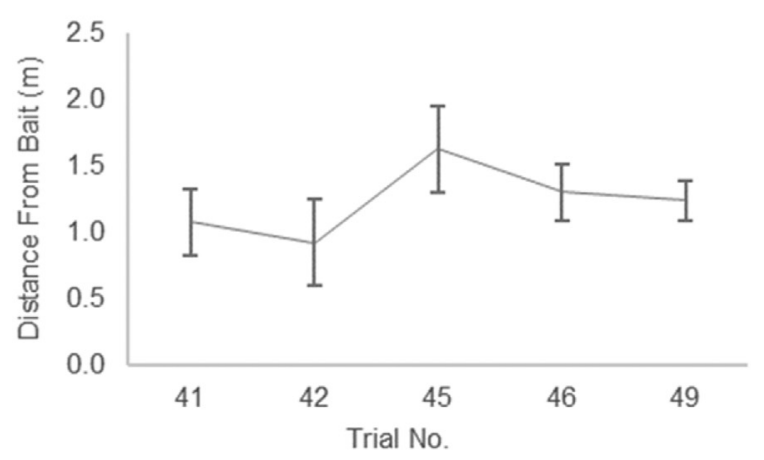

Fig. 4. Mean distance ( \pm standard error) between shark and bait for sharks M1 to M4 (those with more than 1 interaction). Includes data from trials where Rpela $v 2$ was active and not active. 
device was active and not active. Interestingly, for number of passes before an interaction and number of passes regardless of whether there was a bite or interaction, this was apparent only when Rpela v2 was not active. It is unclear why this may be the case.

Finally, it is worth considering the role that personal deterrents could play within broader solutions to the challenging public safety problem of unprovoked shark bite. At a time when authorities tend to be focusing protection at the beach-wide scale [4], [16], [17], the results of this and other studies indicate that some commercially available personal deterrents, but not all (see [6,7], along with behavioural choices (e.g. not surfing at dusk or adjacent to river mouths after river flooding) would reduce the risk to surfers where beach-wide systems were not operating or have limited potential to be effective (see [17]. Unlike swimmers, surfers cant generally be confined to a small location (e.g. tens or hundreds of metres between a marked area patrolled by surf lifesavers and lifeguards) and are generally in deeper water than swimmers. They are not allowed in patrolled areas which are exclusively designated to swimmers and often frequent the reefs and headlands between or at the ends of beaches which cannot practically be covered by beach-wide protection systems. Although the decision to use an individual deterrent and the exact nature of that deterrent is currently a personal decision (i.e. not made by authorities at any level), there is potentially scope for authorities to provide advice regarding the types of personal deterrents that it considers (based on the results of scientific testing) appropriate for surfers to use. Authorities could also make education material available to surfers, so that they are informed about the likely effectiveness of deterrents on a given day under a specific set of conditions. [18] have indicated that public education should be an important part of any strategy that differs from one based on traditional catch and kill shark bite mitigation methods.

\section{Conclusions}

The Rpela v2 is an electric device for surfers that has undergone modifications to strengthen its electric field with a view to improving its effectiveness. This study at Salisbury Island, Western Australia demonstrated that it significantly reduced the probability of a bite or interaction with white sharks, and, when one did occur, the time to bite. Sharks also kept a greater distance from the bait when Rpela v2 was active. Thus, the risk of a bite occurring is expected to be less when the device is used. Importantly, Rpela v2 did not completely remove the risk of shark bite but is expected to benefit surfers by reducing the probability of a shark bite by a meaningful level and potentially giving surfers more time to leave the water when in the presence of a dangerous shark. Overall, the reduction in risk of shark bite demonstrated here met the benchmark suggested by [7] for a shark deterrent to be considered by the public to be effective. Notwithstanding these results, given this trial was limited to a small sample size of seven individuals we recommend that the experiment is repeated on other white sharks and other species to verify the effectiveness of the device.

\section{Conflict of interest statement}

The scientists undertaking the field trials in our experiments were independent and had no financial relationship with the manufacturers of Rpela V2 or Cardno. None of the scientists involved in preparing this manuscript have an ongoing financial or other material relationship with the manufacturers of Rpela v2.

\section{References}

[1] Amin R, Ritter E, Kennedy PA. A geospatial analysis of shark attack rates for the east coast of Florida: 1994-2009. Mar Freshw Behav Physiol 2012;45(3):185-98.

[2] Chapman BK, McPhee DP. Global shark attack hotspots: identifying the underlying factors behind increased unprovoked shark bite incidence. Ocean Coast Manag 2016;133: 72-84.

[3] McPhee DP. Unprovoked shark bites: are they becoming more prevalent? Coast Manag 2014;42(5):478-92.

[4] Cardno (Unpublished results a). Shark deterrents and detectors: review of bather protection technologies. Report prepared for New South Wales Department of Primary Industries.

[5] Hart NS, Collin SP. Shark senses and shark repellents. Integr Zool 2015;10:38-64.

[6] Egeberg CA, Kempster RM, Hart NS, Ryan L, Chapuis L, Kerr CC. Not all electric shark deterrents are made equal: effects of a commercial electric anklet deterrent on white shark behaviour. PloS One 2019;14(3):e0212851. https:// doi.org/10.1371/journal.pone.0212851.

[7] Huveneers C, Whitmarsh S, Thiele M, Meyer L, Fox A, Bradshaw CJA. Effectiveness of five personal shark-bite deterrents for surfers. PeerJ 2018;6. https://doi.org/10.7717/ peerj.5554. e5554.

[8] Murray RW. The response of the ampullae of Lorenzini of elasmobranchs to electrical stimulation. J Exp Biol 1962;39: 119-28.

[9] Kempster R, Egeberg C, Hart N, Ryan L, Chapuis L, Kerr C, et al. How close is too close? The effect of non-lethal electric fields on white shark behaviour. PloS One 2016;11(7): e0157717.

[10] Huveneers C, Rogers PJ, Semmens J, Beckmann C, Kock AA, Page B, et al. Effects of an electric field on white sharks: in situ testing of an electric deterrent. PloS One 2013;8(5): e62730.

[11] Smit CF, Peddemors VM. Estimating the probability of a shark attack when using an electric repellent. South African Journal of Statistics 2003;37:59-78. 
[12] Nasby-Lucas N, Domeier ML. Use of photo identification to describe a white shark aggregation at Guadalupe Island, Mexico. In: Domeier ML, editor. Global perspectives on the biology and life history of the white shark. Florida: CRC Press; 2012. p. 381-92.

[13] Nazimi L, Robbins WD, Schilds A, Huveneers C. Comparison of industry-based data to monitor white shark cage-dive tourism. Tourism Manag 2018;66:263-73.

[14] Arnold TW. Uninformative parameters and model selection using akaike's information criterion. J Wildl Manag 2010; 74(6):1175-8.

[15] Towner AV, Leos-Barajas V, Langrock R, Schick RS, Smale MJ, Kaschke T, et al. Sex-specific and individual preferences for hunting strategies in white sharks. Funct Ecol 2016;30(8):1397-407.

[16] Cardno (Unpublished results b). Queensland shark control program: review of alternative approaches. Report prepared for Queensland Department of Agriculture and Fisheries.

[17] McPhee DP, Blount C, Lincoln Smith MP, Peddemors VM, 2021. A comparison of alternative systems to catch and kill for mitigating unprovoked shark bite on bathers or surfers at ocean beaches. Ocean Coast Manag. https://doi.org/10.1016/ j.ocecoaman.2020.105492.

[18] Pepin-Neff CL, Wynter T. Reducing fear to influence policy preferences: an experiment with sharks and beach safety policy options. Mar Pol 2018;88:222-9. 